\section{Impact of Information Type and Source on Pollinator-friendly Plant Purchasing}

\author{
Benjamin L. Campbell ${ }^{1}$ and William Steele ${ }^{1}$
}

\begin{abstract}
AdDitIONAL INDEX wORDs. buying habits, consumer behavior, neonicotinoids, pollinator decline

SUMMARY. The number of pollinators has been reported to be decreasing for the past several decades. Numerous sources (e.g., climate change, pesticides, loss of habitat) have been noted as potential contributing factors to the decline. With respect to the green industry, the impact of pesticides on pollinator decline and consumer response to this impact is of critical importance. Although no definitive link exists of pesticides being a major contributing factor to pollinator decline, some retailers have banned their suppliers from using certain pesticides. As various sources (e.g., universities, media, activist groups) provide information (both positive, neutral, and negative) about the impact of pesticides on pollinators, no information exists regarding how consumers value such information. Using a sample of Connecticut consumers, this study evaluates how both information source and information type impact a consumer's decision to purchase pollinator-friendly plants in the future. The study finds that consumers exposed to either neutral (no link between pesticides and pollinator decline) or negative (link between pesticides and pollinator decline) information from universities and major media outlets indicate they will purchase more pollinator-friendly plants compared with the no information (control) treatment. The results show that information from the federal government, nursery/greenhouse industry associations, and environmental activist groups have the same impact on self-reported future pollinator-friendly plant purchasing as the no information group.
\end{abstract}

$\mathrm{P}$ ollinators play an integral part in the reproductive process of $75 \%$ to $95 \%$ of all flowering plants (Ollerton et al., 2011; U.S. Fish and Wildlife Service, 2019a), but the world has seen a substantial reduction in the abundance of pollinators (Pollinator Health Task Force, 2015). Many of the world's fruits and vegetables are dependent on pollinators, so the reduction in pollinators has the potential to inflict considerable economic damage to both the United States and the rest of the world. Of the leading 57 single crops, 39 of them are dependent to some degree upon pollinators, with the production volume of these 39 crops representing $35 \%$ of global food

$\overline{\text { Received for publication } 29 \text { July 2019. Accepted for }}$ publication 18 Nov. 2019.

Published online 19 December 2019

${ }^{1}$ Department of Agricultural and Applied Economics, University of Georgia, 147 Cedar Street, Athens, GA 30602

This research was funded via a grant from the U.S. Department of Agriculture/Connecticut Specialty Crop Block Grant Program.

B.L.C. is the corresponding author. E-mail: bencamp@ uga.edu.

This is an open access article distributed under the $\mathrm{CC}$ BY-NC-ND license (https://creativecommons.org/ licenses/by-nc-nd/4.0/).

https://doi.org/10.21273/HORTTECH04473-19 production (Klein et al., 2007). It is estimated that pollinators contribute between $5 \%$ and $8 \%$ of market value to annual global crop production, which equated to between $\$ 235$ billion and $\$ 577$ billion in 2015 dollars (Potts et al., 2017). In the United States, it is estimated that pollinators contribute $\$ 20$ billion to $\$ 40$ billion to agriculture production (Calderone, 2012; Wildlife Habitat Council, 2005). Honey bees (Apis mellifera), in particular, account for $\$ 10$ billion to $\$ 20$ billion (Calderone, 2012).

Although some pollinators have declined steeply over time, other pollinators have experienced weak declines to even increasing abundance (Bartomeus et al., 2013). However, the decline of bees (Apis sp.) in some areas has affected both unmanaged wild bees and commercially managed domesticated bees. Recently, the rusty-patched bumble bee (Bombus affinis) was added to the endangered species list. This marks the first time a bee has been added to the endangered species list (U.S. Fish and Wildlife Service, 2019b). The decline of domesticated honeybee colonies has seen the number of managed colonies decreasing from a little more than 4 million in 1980 to just more than 2.5 million in 2015 (Pollinator Health Task Force, 2015). This decrease has resulted in changes to U.S. regulatory policy-notably, the relaxing of the prohibition of honeybees and honeybee genetic material imports into the United States to meet demand for pollinators (Federal Register, 2004).

As agricultural producers look to ensure pollinators are accessible to pollinate their crops, researchers are working to understand the loss in pollinators. As noted by the Pollinator Partnership (Johnson, 2010), from the 1990s to the mid 2000s, colony losses averaged $\approx 18 \%$ per year. However, from 2006 to 2014 , the average colony losses were $\approx 30 \%$ (van Engelsdorp et al., 2014). Most of the hypothesized theories for pollinator decline have focused on causes such as the loss of native habits, pesticides, diseases, weather, and parasites as significant contributing factors to the general decline of pollinators (Johnson and Corn, 2015; National Academies Press, 2007).

As pollinator issues have come to the forefront, many consumers and activists have advocated for the removal of commonly used pesticides, such as neonicotinoids, from producer use. Retail outlets, including Home Depot (Atlanta, GA) and Lowes (Morresville, NC), have banned their suppliers from using neonicotinoids on plants to be sold in their stores (Bose and Orr, 2015; Home Depot, 2016). Furthermore, the state of Maryland banned consumer use of pesticides that contain neonicotinoids starting in 2018 (Wood, 2016).

As noted by Blacquière et al. (2012) and Decourtye and Devillers (2010) in their literature reviews on the effects of neonicotinoids, there is no concrete evidence that correct use of neonicotinoids are the main cause of pollinator decline. However, consumers face a barrage of information from various groups (e.g., media, activists, universities) that often contain conflicting messages about the impact of pesticides on pollinator decline. The decision about which sources to trust can be difficult. Often, the level of trust an individual consumer has about a news source and/or type of information (neutral or negative) is conditionally 
dependent upon characteristics such as age, income, and political party affiliation (McCluskey et al., 2016; Mitchell et al., 2016).

Although there is a body of literature that focuses on environmentally friendly labeling (Behe et al., 2013; Khachatryan et al., 2014; Rihn et al., 2015; Yue et al., 2011), bee-friendly labeling (Wollaeger et al., 2015), pollinator-friendly labeling (Khachatryan et al., 2018), and pesticide labeling (Rihn and Khachatryan, 2016), little is known about how varying information sources and type of information will impact a consumer's intention to purchase pollinator-friendly plants. The aim of this study was to understand more fully how information communicated to consumers influenced their intended purchasing habits for pollinator-friendly plants. Specifically, the study looked at the source of information (e.g., from a university, major media outlets, activist group) and type of information (i.e., linking and not linking pollinator decline to pesticides) on consumer-indicated future purchasing of pollinatorfriendly plants for their landscape. We hypothesize that information from seemingly "unbiased" sources (university and federal government) would have a significant impact compared with providing no information, whereas information from seemingly "biased" sources (nursery/ greenhouse industry and environmental activist groups) would not be different from the no-information group. Furthermore, we hypothesize that linking pesticides to pollinator decline would increase the likelihood of a consumer purchasing a pollinator-friendly plant compared with not providing any information. By understanding the impact of messaging from different sources, industry associations, policymakers, and stakeholders gain a better understanding of how their messaging will influence consumer decision making and of policies at the state and regional levels.

\section{Materials and methods}

In Summer 2016, an internal review board approved (\#X15-129) an online survey to be administered in Connecticut. Potential respondents were asked to participate via e-mail from the database of Global Market Insight,
Inc. (Lightspeed Research, Warren, NJ) with respondents choosing to participate directed to the study. As a result of the funding agency's interest in the Connecticut market, respondents were limited to the state of Connecticut. Furthermore, the survey was restricted to respondents 18 years old or older, with women being oversampled because they have been shown to be the primary shoppers in a majority of households (Flagg et al., 2013; Wolfe, 2013; Zepeda, 2009). Around 1200 respondents completed the survey, but because only respondents indicating they had a lawn or landscape were asked the pollinator-friendly plant purchasing questions, the final analysis included 785 respondents.

The overall online survey tended to be representative of the average Connecticut resident (Table 1 ). The median age for Connecticut is 40 years of age, with 46 years the median age of the survey sample (U.S. Census Bureau, 2015). The difference in age is largely a result of the sample excluding respondents younger than the age of 18 years whereas the Connecticut estimation includes persons younger than 18 years of age. Household median income of the sample was $\$ 75,000$, whereas the Connecticut median household income is $\$ 70,000$ (U.S Census Bureau, 2011). To this end, the results are generalizable outside of the survey sample only as much as the sample represents the overall views and perceptions of the population as a whole. Although we cannot guarantee that the sample is generalizable, we have a range of demographics, political affiliations, and so on, that give some indication that the sample results can be generalized within and outside of Connecticut.

EXPERIMENTAL DESIGN AND ANALYSIS. There are several ways the impact of information type and information source on pollinatorfriendly plant decision making can be measured. Common approaches include revealed preference (e.g., discrete choice analysis, eye tracking, biometric tools.) and stated preference (e.g., contingent valuation). Although revealed preference studies may mimic real-world decision making more accurately, we used the stated preference approach in this study. The stated preference format was used for two reasons: 1) ease of use and 2) comparison of treatments more than magnitude of treatment. With respect to ease of use, only one question was required to identify the impact of a treatment compared with multiple questions needed for most revealed preference experiments. Also, given we were interested in treatment comparisons and not the magnitude, potential biases associated with stated preference surveys would not be as problematic, given the impact of the biases would be canceled out as a result of the random nature of treatment assignment. For instance, if survey respondents inflated their likeliness to purchase a pollinator-friendly plant, then this inflation would be distributed randomly across treatments, implying the treatment comparisons should not be biased, although the likeliness values would be biased.

Therefore, to assess the impact of type of information and source of information on potential future pollinator-friendly plant purchasing, respondents were assigned randomly to a treatment group upon entering the survey (Table 2). The treatment groups varied by source of information and the type of information. With respect to type of information, respondents saw a message indicating whether there was a linkage or no linkage between pesticides as a contributor to pollinator decline throughout the United States. The message was accredited to a different source, which included university research, major media outlets, federal government, nursery or greenhouse industry, or environmental activist groups. Two other treatment groups were included: control (no information) and a no-source generic information treatment that presented that pollinator numbers have been in decline, although no specific cause has been determined.

As respondents started the survey, they were assigned randomly to one of the treatment groups. This equates to $\approx 65$ respondents in each of the 12 treatment groups. After reading the message associated with the treatment, respondents were asked "What is the likelihood that you will purchase more pollinator-friendly plants for your home landscape during the 
Table 1. Descriptive statistics of respondents for a 2016 pollinator-friendly plant purchasing survey of Connecticut residents.

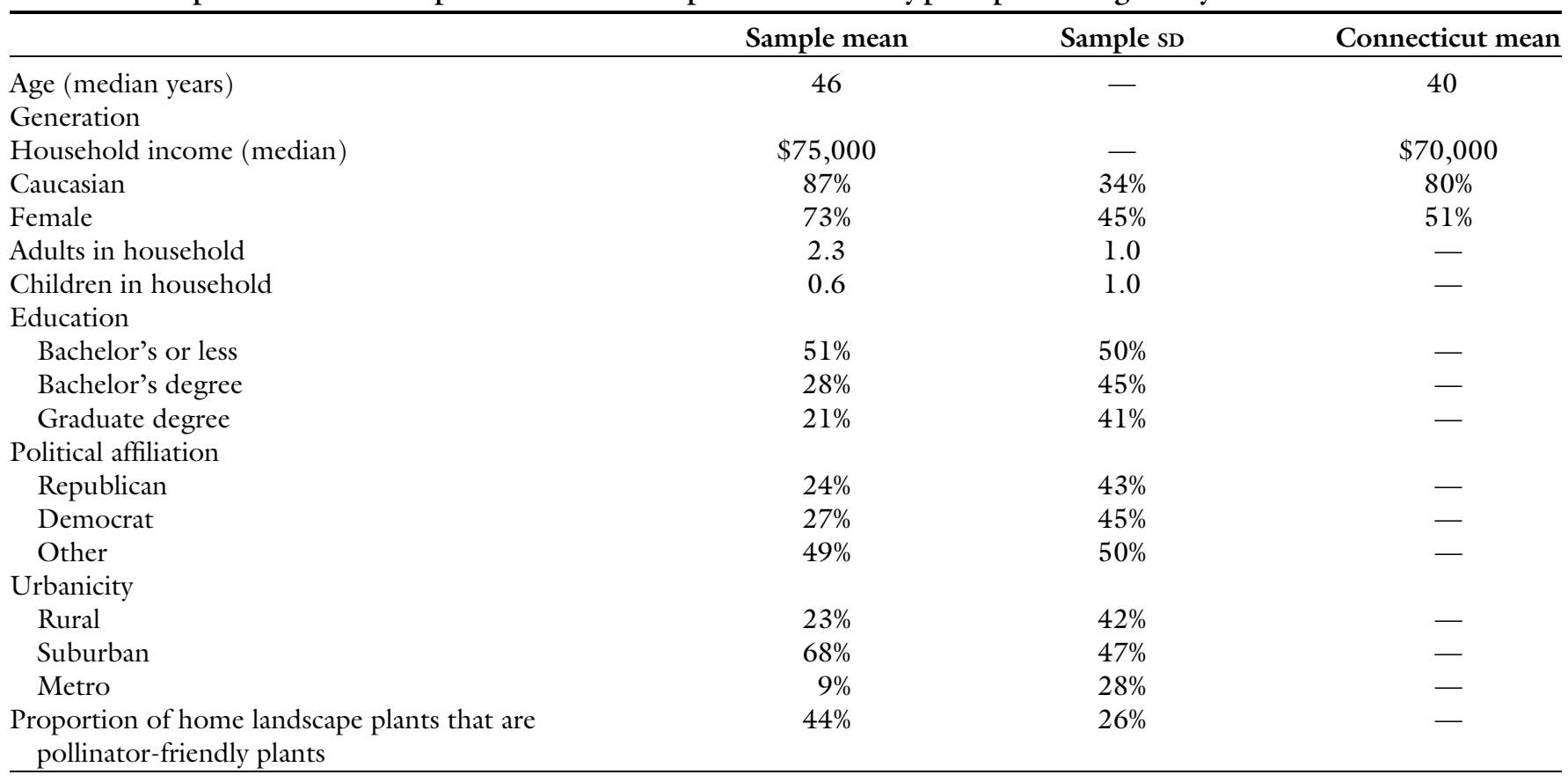

Table 2. Source and type of information used in a 2016 pollinator-friendly plant purchasing survey of Connecticut residents to test impacts of varying treatments on the purchasing of pollinator-friendly plants.

\section{Information source} Statement

Control, no information

Generic information

No linkage

Linkage

Information source

Environmental activist group

Federal government

Major media outlets

Nursery/greenhouse industry

University research

next year?" Respondents answered the question via marking their likelihood on a continuous line scale, where 0 is extremely unlikely, 50 is neither likely/unlikely, and 100 is extremely likely.

About 3\% and $9 \%$ of the sample were censored on the left (at 0 ) or right (at 100) on the 100-point scale. Failure to account for the censored nature of the data can result in biased results. Thereby, censoring was accounted for within the data by using the two-limit Tobit model developed by Rossett and Nelson (1975). The model can be represented as

$$
\begin{gathered}
y_{i}^{*}=\beta^{\prime} x_{i}+\varepsilon_{i}(i=1, \ldots, \mathrm{n}) \\
y_{i}=\left\{\begin{array}{ll}
0 & \text { if } y_{i}^{*} \leq 0 \\
y_{i}^{*} & \text { if } 0<y_{i}^{*}<100 \\
100 & \text { if } y_{i}^{*} \geq 100
\end{array} \quad(i=1, \ldots, \mathrm{n})\right.
\end{gathered}
$$

where $y_{i}^{*}$ is a latent variable that is not observed at values less than zero or values greater than $100, x$ is a matrix of explanatory variables, $\beta$ is a vector of coefficients, and $\varepsilon$ is an independently and normally distributed error term with zero mean and variance $\sigma^{2}$. The $x$ matrix of explanatory variables included demographics, political affiliation, urbanicity, and percent of pollinatorfriendly plants in the respondent's landscape, as well as treatment indicators. Political affiliation and urbanicity were included to control for respondent views on pesticides and regulations so that the treatment group impacts could be isolated. To obtain the coefficient, estimates were maximized using the likelihood function in Eq. [2] (Davidson and McKinnon 1993): 


$$
\begin{gathered}
\sum_{y_{t}^{L} \leq y_{t}^{*} \leq y_{t}^{U}} \log \left\{\frac{1}{\sigma} \phi\left[\frac{1}{\sigma}\left(y_{t}-x_{t} \beta\right)\right]\right\} \\
+\sum_{y_{t}^{*}<y_{t}^{L}} \log \left\{\phi\left[\frac{1}{\sigma}\left(y_{t}^{L}-x_{t} \beta\right)\right]\right\} \\
+\sum_{y_{t}^{*}>y_{t}^{U}} \log \left\{\phi\left[-\frac{1}{\sigma}\left(y_{t}^{U}-x_{t} \beta\right)\right]\right\}
\end{gathered}
$$

The estimated $\beta$ coefficients from Eq. [2] are not interpretable as marginal effects (Gould et al., 1989). To obtain the correct marginal effects, unconditional marginal effects, conditional marginal effects, and the probabilities of being uncensored by using $\mathrm{McDo}^{-}$ nald and Moffitt decomposition (McDonald and Moffitt, 1980) were captured. Only the probabilities of being uncensored as well as the conditional marginal effects in this article are reported here. The probabilities of being uncensored represent how likely a respondent was to have chosen a value between the bounds ( 0 and 100). The conditional marginal effects represent changes from the mean (continuous variables) or changes from the base (categorical variables) values for those responses within the bounds. The analysis was conducted using Stata/SE (version 14.2; StataCorp, College Station, TX).

\section{Results}

Of the 785 respondents, they indicated that, on average, $44 \%$ of the plants in their lawn/landscape were pollinator friendly. Table 3 indicates that both source and type of information produced somewhat similar results on respondent likelihood of planting pollinator-friendly plants within their home landscape. The range was between 59.5 (no source and no information) and 65.2 (no source and generic information) on the likeliness scale, which equates to slightly more likely to plant pollinator-friendly plants in their landscape. Of interest, the lowest rating was for the control group, in which no information was given, and all other treatments had an increased likelihood to add pollinator-friendly plants to their landscape.

TOBIT MODEL RESULTS : Probability of BeINg UNCENSORed. Table 4 shows the probability of being uncensored and the conditional marginal effects from the Tobit model. With respect to the probability of being uncensored, older consumers were more likely to be uncensored than younger consumers, as were females compared with males. For instance, females were $2.5 \%$ less likely to be censored than males. Furthermore, as the percentage of pollinator-friendly plants in the home landscape increased by $1 \%$, they were less likely to be censored. With respect to the treatment groups, the groups did not contributed significantly to respondents being censored

Table 3. Means and sDs associated with varying treatments from a 2016 pollinator-friendly plant purchasing survey of Connecticut residents.

\begin{tabular}{llccc}
\hline & & \multicolumn{2}{c}{$\begin{array}{c}\text { Likelihood of purchasing } \\
\text { more pollinator-friendly } \\
\text { plants next yr (0-100 } \\
\text { scale) }\end{array}$} \\
\cline { 3 - 5 } Source & Information type & Mean & SD & Median \\
\hline No source (control group) & No information & 59.5 & 24.4 & 56.0 \\
No source & Generic & 65.2 & 22.5 & 68.0 \\
Environmental activist group & Link & 63.0 & 25.7 & 65.0 \\
Environmental activist group & No link & 62.5 & 25.0 & 57.0 \\
Federal government & Link & 61.8 & 25.0 & 61.5 \\
Federal government & No link & 61.8 & 26.6 & 65.0 \\
Major media outlets & Link & 64.9 & 24.2 & 64.0 \\
Major media outlets & No link & 63.7 & 25.3 & 64.0 \\
Nursery/greenhouse industry & Link & 60.5 & 24.5 & 62.5 \\
Nursery/greenhouse industry & No link & 65.1 & 25.1 & 70.0 \\
University & Link & 65.0 & 24.0 & 58.0 \\
University & No link & 63.8 & 27.0 & 65.5 \\
\hline${ }^{2} 0=$ extremely unlikely, $50=$ neither likely/unlikely, $100=$ extremely likely. & &
\end{tabular}

${ }^{\mathrm{z}_{0}}=$ extremely unlikely, $50=$ neither likely/unlikely, $100=$ extremely likely.

or uncensored. The only exception was for no source-generic information, with respondents in this treatment $6.1 \%$ less likely to be censored.

TOBIT MODEL RESULTS: MARgINAL EFFECT CONDITIONAL ON BEING UNCENSORED. When comparing demographics and treatments, select demographics and treatments are seen to impact the likelihood of adding pollinator-friendly plants (Table 4). Notably, respondents having a graduate degree were $3.5 \%$ more likely (3.5 units on the 100point scale) to indicate they would add more pollinator-friendly plants to their home landscape during the next year compared with a respondent with a bachelor's degree. Furthermore, females were $4 \%$ more likely to indicate they would add a pollinator-friendly plant for every one-unit increase in the mean, whereas the aggregate likelihood decreased by $9.8 \%$ for every year increase from the average age. The average respondent's likelihood increased by $0.3 \%$ for every percentage increase from the mean of current pollinators in their home landscape. This implies that consumers who have more pollinator-friendly plants in their landscape are more inclined to purchase more pollinator-friendly plants than consumers with less pollinator-friendly plants in their landscape. Most likely this is a result of consumers with more pollinatorfriendly plants seeing the value or perceiving a value to adding more pollinator-friendly plants to their landscape.

With respect to treatments, the no source-generic information treatment increased the average respondent's score by $6.5 \%$ compared with the control group (no information) (Table 4). This implies that bringing consumer attention to decreasing pollinator numbers can influence the decision-making process of consumers even when no direct cause or source of information is provided. Furthermore, an informational message from a university source with either information linking or not linking pesticides to pollinator decline resulted in a $6.6 \%$ and $6.6 \%$ increase in likelihood, respectively. A major media outlets message linking and not linking pesticides to pollinator decline also generated a $5.2 \%$ and $5.6 \%$ increase, respectively. However, 
Table 4. Tobit results estimating the probabilities and marginal effects using data from a 2016 pollinator-friendly plant purchasing survey of Connecticut residents.

\begin{tabular}{|c|c|c|c|c|c|c|}
\hline \multirow[b]{2}{*}{ Treatment } & \multicolumn{3}{|c|}{ Probability of being uncensored } & \multicolumn{3}{|c|}{$\begin{array}{l}\text { Marginal effect conditional on } \\
\text { being uncensored }\end{array}$} \\
\hline & Coefficient & SE & $P$ & Coefficient & SE & $P$ \\
\hline No source, generic & -0.061 & 0.035 & 0.079 & 6.548 & 2.850 & 0.022 \\
\hline University, link & -0.064 & 0.040 & 0.106 & 6.630 & 3.071 & 0.031 \\
\hline University, no link & -0.063 & 0.039 & 0.106 & 6.578 & 3.051 & 0.031 \\
\hline Major media outlets, link & -0.045 & 0.032 & 0.152 & 5.168 & 2.902 & 0.075 \\
\hline Major media outlets, no link & -0.051 & 0.036 & 0.162 & 5.550 & 3.096 & 0.073 \\
\hline Federal government, link & -0.042 & 0.035 & 0.232 & 4.733 & 3.192 & 0.138 \\
\hline Federal government, no link & -0.032 & 0.032 & 0.316 & 3.816 & 3.187 & 0.231 \\
\hline Nursery/greenhouse industry, link & -0.008 & 0.026 & 0.755 & 1.107 & 3.356 & 0.741 \\
\hline Nursery/greenhouse industry, no link & -0.042 & 0.034 & 0.219 & 4.797 & 3.144 & 0.127 \\
\hline Environmental activist group, link & -0.026 & 0.028 & 0.357 & 3.216 & 3.027 & 0.288 \\
\hline Environmental activist group, no link & -0.019 & 0.027 & 0.476 & 2.466 & 3.091 & 0.425 \\
\hline Age (median years) & 0.001 & 0.000 & 0.028 & -0.098 & 0.044 & 0.026 \\
\hline Caucasian & -0.015 & 0.011 & 0.174 & 2.469 & 2.036 & 0.225 \\
\hline Female & -0.025 & 0.009 & 0.004 & 4.047 & 1.529 & 0.008 \\
\hline \multicolumn{7}{|l|}{ Political affiliation } \\
\hline Republican & -0.011 & 0.014 & 0.449 & 1.461 & 1.842 & 0.428 \\
\hline Other & 0.003 & 0.011 & 0.801 & -0.390 & 1.552 & 0.801 \\
\hline \multicolumn{7}{|l|}{ Urbanicity } \\
\hline Rural & -0.015 & 0.020 & 0.447 & 2.087 & 2.570 & 0.417 \\
\hline Suburban & -0.006 & 0.016 & 0.705 & 0.898 & 2.416 & 0.710 \\
\hline Adults in household & -0.007 & 0.005 & 0.118 & 1.056 & 0.671 & 0.116 \\
\hline Children in household & -0.001 & 0.005 & 0.798 & 0.184 & 0.722 & 0.798 \\
\hline \multicolumn{7}{|l|}{ Education } \\
\hline Bachelor's or less & -0.005 & 0.011 & 0.619 & 0.785 & 1.579 & 0.619 \\
\hline Graduate degree & -0.027 & 0.016 & 0.098 & 3.478 & 1.859 & 0.061 \\
\hline Household income (median dollars) & 0.000 & 0.000 & 0.178 & 0.000 & 0.000 & 0.176 \\
\hline $\begin{array}{l}\text { Percentage of home landscape plants that are } \\
\text { pollinator-friendly plants }\end{array}$ & -0.002 & 0.000 & 0.000 & 0.314 & 0.027 & 0.000 \\
\hline Observations (no.) & \multicolumn{6}{|c|}{785} \\
\hline Likelihood ratio chi-square & \multicolumn{6}{|c|}{175.2} \\
\hline$P$ value $>$ chi-square & \multicolumn{6}{|c|}{0.000} \\
\hline Log-likelihood & \multicolumn{6}{|c|}{$-3,303.8$} \\
\hline Pseudo- $R^{2}$ value & \multicolumn{6}{|c|}{$2.6 \%$} \\
\hline Left censored (ratings at 0 ) & \multicolumn{6}{|c|}{$3.2 \%$} \\
\hline Right censored (ratings at 100) & \multicolumn{6}{|c|}{$8.9 \%$} \\
\hline
\end{tabular}

information either linking or not linking pesticides to pollinator decline from the federal government, nursery/greenhouses, and environmental activists had no difference compared with the control (no source and no information). This result is not wholly surprising given that nurseries/greenhouses and environmental activists could be considered biased sources. However, the lack of significance of federal government coefficients is interesting. This result could be the result of numerous reasons, such as not trusting federal information because the government may be thought of as having an agenda to respondents being inundated with environmental information from the federal government, thereby diluting the impact of pollinator-specific information.

\section{Conclusions}

To consumers, all sources of information are not the same. The level of trust, or lack thereof, consumers place in a source is influenced by a multitude of factors. Firms that can identify which sources of information are trusted by their consumer base and which sources are not, can develop effective marketing strategies that will aid their marketing efforts.

With regard to the findings, it is clear the source of information matters, with the type of information (link vs. no link of pesticides) playing less of a role. Information emanating from university research, regardless of blaming pollinator declines on pesticides, influences consumers reported future purchasing decisions of pollinatorfriendly plants. When the source of information is major media outlets, consumers will change their purchasing habits if the information links or does not link pesticide use to pollinator declines. Information originating from nurseries/greenhouses, the federal government, and environmental activist groups have little impact on respondents' reported future purchasing of pollinator-friendly plants.

Based on these findings, producers, retailers, policymakers, and stakeholders wanting to increase pollinator-friendly plants sales should provide information to their clientele 
from universities or major media outlets. These entities could also provide generic information that highlights the plight of pollinators. Using other information sources (i.e., federal government, nursery/greenhouse, environmental activist group) will provide a similar response in moving respondents to purchase more pollinator-friendly plants as providing no information. However, linking pesticides to pollinator-friendly decline had little effect on increasing purchasing. Thereby, retailers can avoid putting unproved linkages on their messages and focus more on providing information about pollinator decline in general.

Providing information about pollinator decline should increase the demand for pollinator-friendly plants, although it would most likely be at the expense of nonpollinator-friendly plants. Therefore, before advertising about pollinator-friendly plants, retailers should determine their overall business objective. For instance, retailers who want to maximize revenue should understand which plants give the greatest margin (price received less the cost of producing) and focus their efforts on increasing the demand for those plants. If a nonpollinatorfriendly plant has a greater margin, then they should think about whether they should provide information about pollinators. However, if a pollinatorfriendly plant has a greater margin, then providing pollinator information would most likely increase sales. Another objective could be to increase the number of pollinator-friendly plants sold, which means that providing pollinator information could accomplish this objective.

There are several limitations to the study and areas for future research. With respect to limitations, the study was conducted using Connecticut consumers only, implying results are only generalizable to other areas in so much as Connecticut consumers are guided by the same purchasing processes as other populations. Furthermore, using specific industry associations, major media outlets, universities, and/or activist groups could potentially lead to different results than the more generalized results found by using sources that are more generic (e.g., universities instead of specific universities) in nature. As for future work, examining the impact of specific sources and varying the types of information could help firms have a more in-depth understanding of how information and sources impact their customer base.

\section{Literature cited}

Bartomeus, I., J.S. Ascher, J. Gibbs, B.N. Danforth, D.L. Wagner, S.M. Hedtke, and R. Winfree. 2013. Historical changes in northeastern US bee pollinators related to shared ecological traits. Proc. Natl. Acad. Sci. USA 110:4656-4660.

Behe, B.K., B.L. Campbell, C.R. Hall, H. Khachatryan, J.H. Dennis, and C. Yue. 2013. Consumer preferences for local and sustainable plant production characteristics. HortScience 48:200-208.

Blacquière, T., G. van Gestel, and V. Mommaerts. 2012. Neonicotinoids in bees: A review on concentrations, sideeffects and risk assessment. Ecotoxicology 21:973-992.

Bose, N. and B. Orr. 2015. Lowe's to eliminate pesticides that hurt crop pollinating honeybees. 10 June 2019. <https:// www.reuters.com/article/us-lowespesticides-idUSKBN0N023F20150409>.

Calderone, N.W. 2012. Insect pollinated crops, insect pollinators and US agriculture: Trend analysis of aggregate data for the period 1992-2009. PLoS One 7:1-27.

Davidson, R. and J.G. McKinnon. 1993. Estimation and inference in econometrics. Oxford University Press, New York, NY.

Decourtye, A. and J. Devillers. 2010. Ecotoxicity of neonicotinoid insecticides to bees, p. 85-95. In: S.H. Thany (ed.). Insect nicotinic acetylcholine receptors. Adv. Expt. Med. Biol. Springer, New York, NY.

Federal Register. 2004. A rule by the Animal and Plant Inspection Service. 69 FR 61735:61735-61755. 10 Apr. 2019. <https://www.federalregister.gov/ documents/2004/10/21/04-23416/ bees-and-related-articles $>$.

Flagg, L.A., B. Sen, M. Kilgore, and J.L. Locher. 2013. The influence of gender, age, education, and household size on meal preparation and food shopping responsibilities. Public Health Nutr. 17:2061-2070

Gould, B.W., W.E. Saupe, and R.M. Klemme. 1989. Conservation tillage: The role of farm and operator characteristics and the perception of soil erosion. Land Econ. 65:167-182.

Home Depot. 2016. How Home Depot's addressing "neonic" concerns." 12 May 2019. <https://corporate.homedepot. com/newsroom/how-home-depotaddresses-neonicotinoid-concerns $>$.

Johnson, R. 2010. Honey bee colony collapse disorder. Congressional Res. Serv. 7-5700 RL33938. 2 Nov. 2019. <https://fas.org/sgp/crs/misc/ RL33938.pdf>.

Johnson, R. and M.L. Corn. 2015. Bee health: Background and issues for Congress. Congressional Res. Serv. 7-5700 R4343191. 15 June 2019. <https://fas. org/sgp/crs/misc/R43191.pdf>

Khachatryan, H., A. Rihn, B. Behe, C. Hall, B. Campbell, J. Dennis, and C. Yue. 2018. Visual behavior, buying impulsiveness, and consumer behavior. Mktg. Lett. 29:23-35.

Khachatryan, H., C. Yue, B. Campbell, B. Behe, and C. Hall. 2014. The effects of consideration of future and immediate consequences on willingness to pay decisions for environmentally friendly plant attributes. J. Environ. Hort. 32:64-70.

Klein, A.M., B.E. Vaissière, J.H. Cane, I. Steffan-Dewenter, S.A. Cunnigham, C. Kremen, and T. Tscharntke. 2007. Importance of pollinators in changing landscapes for world crops. Proc. Royal Soc 274:303-313.

McCluskey, J.J., N. Kalaitzandonakes, and J. Swinnen. 2016. Media coverage, public perceptions, and consumer behavior: Insights from new food technologies. Annu. Rev. Resources Econ. 8:467-486.

McDonald, J.F. and R.A. Moffitt. 1980. The uses of Tobit analysis. Rev. Econ. Stat. 62:318-321.

Mitchell, A., J. Gottfried, M. Barthel, and E. Shearer. 2016. The modern news consumer: News attitudes and practices in the digital era. 24 June 2019. <https:// www.journalism.org/2016/07/07/ trust-and-accuracy/>.

National Academies Press. 2007. Status of pollinators in North America. 20 June 2019. <https://www.nap.edu/read/ $11761 /$ chapter/5>.

Ollerton, J., R. Winfree, and S. Tarrant. 2011. How many flowering plants are pollinated by animals? Oikos 120:321326.

Pollinator Health Task Force. 2015. National strategy to promote the health of honey bees and other pollinators. 23 June 2019. <https://obamawhitehouse. archives.gov/sites/default/files/microsites/ ostp/Pollinator $\% 20$ Health $\% 20$ Strategy $\%$ 202015.pdf>.

Potts, S.G., V.L. Imperatriz-Fonseca, and H.T. Ngo (eds.). 2017. The assessment report on pollinators, pollination and food production. 21 May 2019. 
<https://www.ipbes.net/sites/default/ files / downloads/pdf/individual_ chapters_pollination_20170305.pdf $>$.

Rihn, A. and H. Khachatryan. 2016. Does consumer awareness of neonicotinoid pesticides influence their preferences for plants? HortScience 51:388-393.

Rihn, A., H. Khachatryan, B. Campbell, B. Behe, and C. Hall. 2015. Consumer response to novel indoor foliage plant attributes: Evidence from a conjoint experiment and gaze analysis. HortScience 50:1524-1530.

Rossett, R.N. and F.N. Nelson. 1975. Estimation of the two-limit probit regression model. Econometrica 43:141146.

U.S. Census Bureau. 2011. State and county quickfacts: Connecticut. 24 Jan. 2017. <http://quickfacts.census.gov/ qfd/states/09000.html>.

U.S. Census Bureau. 2015. Census bureau releases 2010 census demographic profiles for Alaska, Arizona, California, Connecticut, Georgia, Idaho, Minnesota, Montana, New Hampshire, New York, Ohio, Puerto Rico and Wisconsin. 10 Jan.
2017. <https://www.census.gov/ newsroom/releases/archives /2010_ census/cbll-cnl37.html>.

U.S. Fish and Wildlife Service. 2019a. Pollinators. 15 June 2019. <https:// www.fws.gov/pollinators/>.

U.S. Fish and Wildlife Service. 2019b. Rusty patched bumble bee. 31 Oct. 2017. <https://www.fws.gov/midwest/ endangered/insects/rpbb/index.html>.

van Engelsdorp, D., N. Steinhauer, K. Rennich, M. Wilson, K. Baylis, D.M. Caron, K.S. Delaplane, J. Ellis, K. Lee, E.J. Lengerich, J. Pettis, R. Rose, R. Sagili, J. Skinner, A.M. Spleen, D.R. Tarpy, D. Travis, and J.T. Wilkes. 2014. Colony loss 2013-2014. 18 May 2019. <https://beeinformed.org/2014/05/ 15/colony-loss-2013-2014/>.

Wildlife Habitat Council. 2005. Native pollinators. 18 Nov.2018. <https:// plants.usda.gov/pollinators/Native_ Pollinators.pdf>.

Wollaeger, H.M., K.L. Getter, and B.K. Behe. 2015. Consumer preferences for traditional, neonicotinoid-free, bee-friendly, or biological control pest management practices on floriculture crops. HortScience 50:721-732.

Wood, P. 2016. Bee advocates victorious in Maryland general assembly. 14 May 2019. <www.baltimoresun.com/news/ maryland/politics/blog/bal-beeadvocates-victorious-in-general-assembly20160407-story.html>.

Wolfe, A. 2013. Christine Lagarde: On top of the world. 5 Sept. 2018. <https:// www.wsj.com/articles/christine-lagardeon-top-of-the-world-1380934428>.

Yue, C., J. Dennis, B. Behe, C. Hall, B. Campbell, and R. Lopez. 2011. Investigating consumer preference for organic, local, or sustainable plants. HortScience 46:610-615.

Zepeda, L. 2009. Which little piggy goes to market? Characteristics of US farmers' market shoppers. Intl. J. Consum. Stud. $33: 250-257$. 